\title{
DESCOLONIZAÇÃO E A PEDAGOGIA DA SOLIDARIEDADE ${ }^{123}$
}

Rubén A. Gaztambide-Fernández ${ }^{4}$

\section{INTRODUÇÃO}

No início do século XXI, movimentos profundamente contraditórios e paradoxais reconfiguram as relações humanas. Por um lado, o capitalismo neoliberal global e o colapso econômico, a extração de recursos e a degradação ambiental, a invasão e o expansionismo militares estão aumentando a dominação colonial e o sofrimento humano em todo o planeta. Por outro lado, o ressurgimento indígena e o advento da governança indígena em lugares como Chiapas e Bolívia ${ }^{5}$, as (re) articulações em evolução do Movimento (des)Ocupar ${ }^{6}$ e novas alianças diaspóricas e formas de solidariedade econômica, estão apontando possibilidades emergentes para recuperar e redefinir os direitos humanos. Esses movimentos e mudanças complexos e contraditórios estão ligados a um nó causal complexo, com maior contato entre povos díspares; às vezes em conflito e outras, em interação colaborativa, já que vivemos em um mundo de encontros intensificados com a diferença. Deslocamento, movimento, violência, bem como novos modos de se relacionar com outras pessoas ${ }^{7}$ caracterizam esses encontros. Neste contexto, enfrentamos tanto o desafio quanto a oportunidade de repensar ativamente os modos de interação humana e reformular a diferença que a diferença $\mathrm{faz}^{8}$.

\footnotetext{
${ }^{1}$ Agradecimento do autor

Quero agradecer aos editores da/de "Decolonization/Descolonização", Chandni Desai, Aman Sium e Eric Ritskes, pelo excelente feedback e apoio às ideias por mim aqui desenvolvidas. Este artigo provavelmente continuaria sendo um rascunho, se não fosse pelo seus incentivos e paciência. Quero também agradecer aos alunos do meu seminário de Pedagogias da Solidariedade, onde muitas das ideias aqui articuladas, se desenvolveram. Os rascunhos anteriores deste artigo foram apresentados como um "trabalho em andamento" no Centro de Mídia e Cultura na Educação e como um artigo convidado na conferência "Estudos do Currículo Provocador", em 2009.

${ }^{2}$ Artigo pubicado em inglês na Revista Decolonization: Indigeneity, Education \& Society. Vol. 1, No. 1, 2012, pp. 4167.

${ }^{3}$ Tradução: Nelson Santiago. Revisão Técnica: Maria Luiza Süssekind. Apoio CNE/FAPERJ.

${ }^{4}$ Instituto Ontário para Estudos e Educação/ Universidade de Toronto, Canadá.

5 N. da RT: contexto de 2009.

${ }^{6}$ (Un)Occupy Movement, no original.

${ }^{7}$ Nota da RT: Demos relevo à expressão pois o autor vai trabalhar com o conceito de relacionalidade que é aqui entendida como a condição humana que se torna exigência ética na interação entre pessoas humanas. Por oposição, há os modos coloniais de relacionalidade humana.
}

${ }^{8}$ Nota da R.T: quando o relevo for dado pelo autor, não colocaremos nota a partir daqui. 
As características deste momento em particular não são espontâneas ou naturais, mas sim o resultado de dinâmicas complexas de colonização, diásporas e genocídios produzidos tanto pelos Estados Unidos, quanto pelo expansionismo imperialista europeu. A "nova visão de mundo", justificada pelo "evento" de 1492 e suas consequências, impõe persistentemente concepções particulares do que significa ser humano, definindo o que 'importa' como diferença cultural (WYNTER, 1995, 2003). A supremacia branca e a ordem heteropatriarcal impõem violentamente os modos coloniais de relacionalidade humana, fabricando posições de sujeitos por meio de regimes discursivos entrelaçados e interligados de gênero, raça, classe, sexualidade e competências, entre outros. À medida que mais e mais pessoas se relacionam, essas posições de sujeito são amplamente reforçadas - e, às vezes, contestadas - por meio de múltiplos encontros entre pessoas humanas, que são os marcadores definitivos do complexo mundo social na virada do século XXI.

No contexto destas mudanças, educadores são chamados a desempenhar um papel central na construção das condições para um tipo diferente de encontro, um encontro que tanto se opõe à colonização em andamento quanto busca curar as devastações sociais, culturais e espirituais da história colonial. Essa chamada exige o abandono das lógicas tradicionais da educação formal que definiram projetos educacionais nos últimos dois séculos. Também requer ir além das concepções desgastadas de autonomia individual e consciência racional. Essas concepções reconstituem o indivíduo como local de mudança social e, em última análise, baseiam-se na mesma concepção de conhecimento - e de humano/"homem" - que serviu de fundamento para justificar a escravidão, o genocídio e as guerras de conquista (GRANDE, 2004; WYNTER, 1995, 2003). A "Razão", em suas manifestações variadas e contraditórias, até agora falhou em produzir um modo de ser ético que seja capaz de combater satisfatoriamente as forças da colonização.

Os educadores críticos empenhados na descolonização e na crítica antirracista devem esforçar-se em imaginar quais relações humanas poderão emergir das condições atuais, marcadas principalmente pelo aumento da migração e pela instabilidade econômica, ecológica e política. Somos conclamados a imaginar e buscar modos de relacionalidade humana que possam constituir formas de resistência, bem como de cura, à colonialidade das condições atuais. Isso requer uma reformulação de nossas relações e nos encontros com a diferença, no dia-a-dia. "O que está em jogo", de acordo com Judith Butler, "é realmente repensar o humano como um local de interdependência" (Apud TAYLOR, 2008).

Tendo estes desafios em mente, ofereço, nesse artigo, uma visão para uma pedagogia da solidariedade que possa começar a apontar na direção de novas possibilidades de uma educação comprometida com a descolonização e a práxis anti opressiva. Embora a solidariedade seja 
frequentemente lembrada no contexto de projetos políticos comprometidos com a descolonização, também provoca ceticismo enquanto um conceito que pode ser mobilizado para encobrir a própria dinâmica da colonização, que prepara o cenário para - e às vezes é reproduzida por - relações solidárias (TUCK; YANG, 2012). Isso acontece, em parte, porque a solidariedade raramente é teorizada e sua genealogia, como um conceito que evoluiu dentro do contexto da construção das nações europeias, amplamente ignorada. Essa genealogia representa um desafio para a maneira como pensamos e nos envolvemos em projetos de solidariedade, comprometidos com a descolonização. No entanto, como espero demonstrar neste artigo, também é possível articular um conjunto de parâmetros para o engajamento da solidariedade, pedagogicamente, como uma estratégia descolonizadora.

\section{TENTATIVAS FRACASSADAS: DO MULTICULTURALISMO AO COSMOPOLITISMO}

Educadores que trabalham dentro de várias tradições progressistas e reconstrucionistas sociais, fizeram várias propostas para enfrentar os desafios desta colonização contínua. Talvez a mais difundida tenha sido a infinidade de propostas que evoluíram em torno da noção de multiculturalismo. Nos Estados Unidos, o conceito de multiculturalismo evoluiu em resposta às demandas do movimento dos Direitos Civis e aos desafios colocados pela persistência do racismo na era pós-Brown (BANKS, 2009). No Canadá, o multiculturalismo foi, em parte, uma consequência da astuta resposta bicultural ao conflito entre as potências franco-colonial e anglo-colonial em erupção em torno da questão de Quebec, largamente marginalizando - e apagando ainda mais - a continuação da colonização dos povos indígenas (DAY, 2000). Embora apenas no Canadá o multiculturalismo tenha sido inscrito na política federal, nos dois países tornou-se uma força importante nos discursos educacionais, na tentativa de lidar com o problema de como educar uma população cada vez mais diversa.

As críticas ao multiculturalismo não são novas e muitos estudiosos apontaram para as várias limitações de um conceito que, em sua própria etimologia, contém uma concepção antiquada de cultura que não pode deixar de reinscrever os essencialismos coloniais (GOLDBERG, 1994; HALL, 1992; WALCOTT, 2003). O próprio prefixo multi implica fronteiras discretas, mas claras e duradouras, entre esta cultura e aquela cultura ou outra que seja conceitualmente e empiricamente insustentável; e falham, em descrever a dinâmica complexa vivida da mudança cultural. Como Stuart Hall argumentou em seu ensaio "Notas sobre a Desconstrução do Popular": "não há 'culturas' totalmente separadas paradigmaticamente, em uma relação de fixidez histórica" (1981, p. 238). Embora Hall discutisse sobre classe social, seu argumento pode ser estendido à etnia, raça e qualquer outra das categorias sociais em torno das quais as reivindicações culturais são geralmente feitas. 
Esta é a razão pela qual o multiculturalismo canadense, enquanto política ou ideia, tem sido e deve continuar sendo - criticamente instável. Enquanto atua ostensivamente sobre a valorização da diversidade cultural que permeia e enriquece a sociedade canadense, o multiculturalismo opera, também, no sentido de gerenciar e conter diferenças culturais. Além disso, transforma diversidade em uma mercadoria a ser comercializada e vendida tanto pelo estado, quanto pelas corporações. Para conseguir isso, o multiculturalismo impõe concepções ultrapassadas de cultura que exigem que os indivíduos adotem identificações estritamente essencialistas, gerando consequências políticas significativas - porém, muitas vezes negativas. Ou seja, o multiculturalismo exige identidades culturais, "efetivamente deslocando os determinantes político-econômicos das identidades socioculturais em questão, para significantes essencialmente raciais e étnicos" (GOONEWARDENA; KIPFER, 2005, p. 674, itálico original). Isso se manifesta na maneira como o termo é utilizado para lidar com o problema da diferença cultural em vários contextos e instituições, de escolas e museus a festivais de ruas e centros comunitários de artes.

Apesar das várias críticas à ideia do multiculturalismo como inerentemente colonialista, os educadores da América do Norte ainda se apegam ao conceito como se suas vidas dependessem disso. De certo modo isto pode ser estratégico, pois o multiculturalismo é uma política oficial e, na medida em que permanece de tal modo, o engajamento do conceito pode ser politicamente conveniente (PHILLIPS, 2007). Entretanto, como sugere Rita Wong, "embora seja necessário apoiar o multiculturalismo diante dos ataques da supremacia branca, também é importante entender as inadequações do multiculturalismo canadense", particularmente como resposta às injustiças econômica e política (WONG, 2008, p. 159; BANNERJI, 2000).

O fracasso do multiculturalismo em lidar com a injustiça política e sua tendência a impor identidades culturais limitadas, requer uma alternativa crítica, como a sugerida por Butler (1997) e que repensa o humano ao re-centralizar a diferença, concentrando-se mais nas particularidades da interdependência humana, do que nas generalidades da universalidade humana. Tal repensar exige, por um lado, o reconhecimento de como categorias socialmente construídas de raça, etnia, gênero, sexualidade e classe social têm consequências reais e diretas nas condições materiais e simbólicas, que afetam indivíduos e grupos; por outro, exige reconhecer que as consequências de tais condições, nem sempre são previsíveis e que circunstâncias e relacionamentos particulares, permitem ou impedem respostas e modos particulares de estar-com-outros ${ }^{9}$ e de agir no mundo.

\footnotetext{
${ }^{9} \mathrm{~N}$ da R.T: mantivemos a hifenização conforme aparece no original.
} 
Abordagens alternativas que buscam pressionar contra os limites do multiculturalismo evoluíram, como o multiculturalismo crítico e, mais recentemente, uma guinada para o cosmopolitismo com progressivos financiamentos educacionais. Com base na teoria crítica da raça, o multiculturalismo crítico localiza processos de identificação e construção de identidades, dentro de uma estrutura social/jurídica que aborda o papel que a dinâmica de poder desempenha, naquilo que passa a ser visto como culturalmente específico ou relevante (LADSON-BILLINGS, BROWN, 2008). Valorizando o contexto sociopolítico da educação multicultural, tais abordagens buscam desenvolver um conceito mais dinâmico e processual do multiculturalismo, como "um conjunto propositadamente flexível de características em vez de uma definição fixa e estática, que aborde os diferentes contextos das comunidades e o processo de transformação da educação" (NIETO, BODE, KANG, RAIBLE, 2008, p. 179; NIETO, BODE, 2012). As abordagens multiculturais críticas reconhecem, "que a própria escola é um local para a produção da diferença e não apenas um ponto de recepção", onde várias culturas são colocadas em contato (MCCARTHY, REZAI-RASHTI, TEASLEY, 2009, p. 76). Apesar dessa importante mudança, no entanto, dentro de tais alternativas o conceito de diversidade continua a operar como uma palavra substituta, para a maneira como os sistemas governamentais lidam com os problemas mais profundamente dos socius ${ }^{10}$ : raça, classe, gênero e sua expressão na desigualdade fundamental, que a escolaridade produz dentro de sua própria organização do conhecimento" (p. 77).

Na sua crítica à educação multicultural, McCarthy, Rezai-Rashti e Teasley argumentam que dispensar a diversidade como substituição, requer "abandonar o status aurático de conceitos como 'cultura' " identidade 'e' etnia" e reconhecer, por sua vez, "a porosidade vital que existe entre todos os grupos humanos no século XXI” (2009, p. 93). Como alternativa, eles seguem o exemplo de apelos mais recentes a um "ethos cosmopolita", como resposta às falhas do multiculturalismo (por exemplo, HANSEN, 2008, 2010; PINAR, 2009; POPKEWITZ, 2007; TODD, 2009). Paradoxalmente, esses apelos falharam amplamente em reconhecer as maneiras pelas quais o próprio cosmopolitismo restabelece a colonialidade, através da reedição da afirmação descritiva humano/Homem à semelhança do sujeito europeu (branco, masculino, classe alta). Como Walter Mignolo aponta, "projetos cosmopolitas, embora com diferenças significativas, têm trabalhado em dois momentos da modernidade. O primeiro foi um projeto religioso; o segundo era secular. Ambos, porém, estavam ligados à colonialidade e ao surgimento do mundo colonial/moderno" (2000, p. 722).

\footnotetext{
${ }^{10}$ N. da RT: socius pode ser, nesse contexto, traduzido para comunidades.
} 
Mignolo (2000) defende um "cosmopolitismo crítico" que substitui a universalidade pelo que ele chama de "diversalidade", como uma maneira de centralizar a experiência da produção violenta da diferença colonial. No entanto, mesmo o repensar radical do cosmopolitismo de Mignolo retém os fantasmas da filosofia do Iluminismo, que formaram sua emergência no trabalho de Emanuel Kant (1795/1917; HARVEY, 2009; TODD, 2009), e no seu caso, pela insistência na mesma definição racionalista daquilo considerado como humano (BHIMANI; GAZTAMBIDE-FERNÁNDEZ, 2011).

Para Thomas Popkewitz, "se o cosmopolitismo fornece uma maneira de pensar sobre a esperança do futuro, sua tese cultural gera princípios que ordenam as qualidades e características das pessoas que ameaçam esse futuro" (2009, p. 395), especificamente o irracional e limitado, o emotivo "outro". Isso faz parte do que Sharon Todd chama de "linhas de falha do cosmopolitismo, sobre as quais repousam uma série de paradoxos, ambivalências e tensões", sobre a possibilidade de um novo projeto cosmopolita (2009, p. 47). Ao reter o indivíduo como unidade de ação, uma concepção racionalista do humano - ainda que de maneira subjetivista e uma evasão da questão do "outro", o cosmopolitismo reinstitui o sujeito do Iluminismo e, ao longo do caminho, a própria colonialidade que produziram condições presentes (BHIMANI, GAZTAMBIDE-FERNÁNDEZ, 2011).

À luz dessas críticas volto-me ao conceito de solidariedade, como uma possível abertura para repensar estratégias educacionais que possam produzir abordagens diferentes para a descolonização. Diferentemente do multiculturalismo e do cosmopolitismo, o conceito de solidariedade recebeu pouca atenção teórica na literatura educacional. E isso parece notável, dada a frequência com que o conceito é usado, principalmente nas literaturas discutidas acima, como um aspecto importante de qualquer resposta educacional às condições de exploração e colonização. Por exemplo, a solidariedade figura com destaque na "Pedagogia do Oprimido", de Paulo Freire (1970/2005), como um aspecto fundamental de como os "opressores" entram em relações libertadoras com os "oprimidos". Para Freire, a solidariedade consiste no reconhecimento de que a libertação é um projeto coletivo, que requer participação dialógica e uma consciência crítica de como opressor e oprimido são unidos por meio de relações de poder.

No entanto, Freire, como a maioria dos outros autores da tradição crítica, deixa a solidariedade amplamente subteorizada. Em sua introdução para "Multiculturalismo Crítico", Barry Kanpol e Peter McLaren "reconhecem que existem boas razões pelas quais uma política radical de solidariedade tem sido difícil de conceituar" (1995, p. 4). Até o próprio ensaio de Kanpol (1995), com o subtítulo "uma pedagogia da solidariedade fronteiriça", parece confundir solidariedade com empatia, sem qualquer teorização sobre o que implica a solidariedade, de onde vem, como evolui ou porque importa. Em parte, essa falta de teorização deve-se a uma idealização dada como certa, do conceito de 
solidariedade, no escopo dos estudos financiados. Esta lacuna, apresenta uma oportunidade para considerar as maneiras pelas quais, a solidariedade pode fornecer novas visões para abordagens críticas e descolonizadoras da educação.

\section{SOLIDARIEDADE}

Solidariedade é talvez um dos termos mais usados em chamadas para fomento de pesquisas em educação, assim como na retórica da maioria dos movimentos sociais, sejam políticos, educacionais, culturais ou de qualquer outro tipo. É também um dos conceitos mais utilizados e, como argumenta Sally Scholz (2008), de maneira errada. Kurt Bayertz observa que o conceito de solidariedade "compartilha o mesmo destino de outros conceitos da terminologia ética e política, ou seja, não ser definido de maneira vinculativa e, consequentemente, ser usado de maneiras muito diferentes, às vezes contraditórias" (1999, p. 3). Por ser idealizada, a noção geral de solidariedade é mobilizada para uma ampla gama de projetos, sem um conjunto consistente de parâmetros. A solidariedade é frequentemente usada como uma maneira conveniente de expressar certos ideais políticos, sem nenhuma preocupação em articular aquilo o que exatamente se entende por solidariedade, muitas vezes confundindo múltiplos significados. Isso é verdade se o termo está sendo usado dentro da estrutura política e social ou em sua oposição, herdada pela colonização europeia. De fato, uma "solidariedade" descolonizadora - mobilizando o próprio termo - traz consigo as histórias e complexidades de como o termo evoluiu, desde sua etimologia latina original por meio de seu uso em outras línguas coloniais.

Em termos gerais, solidariedade refere-se a tipos particulares de relações sociais entre indivíduos e grupos. Como tal, a solidariedade é usada em referência a uma vasta gama de fenômenos sociais, desde a coesão social aos movimentos sociais, da organização política à organização cívica, do dever religioso à obrigação racial $^{11}$ (?). Scholz argumenta que, em todos esses casos, a solidariedade sempre implica alguma forma de obrigação moral positiva e, portanto, "as diferentes formas ou espécies de solidariedade podem ser diferenciadas de acordo com suas prioridades morais e relações constituintes" (2008, p. 19). Embora a solidariedade sempre tenha um referente idealizado, assim como esse referente depende das características particulares de um grupo de indivíduos, também varia em relação às diferenças e semelhanças. Na maioria das vezes, a solidariedade depende de semelhanças em características, interesses políticos, necessidades sociais ou obrigações morais. $\mathrm{O}$ mais relevante para os projetos de descolonização, ainda que mais raro e complicado de teorizar, é

\footnotetext{
${ }^{11}$ N. da RT: refere-se à essencialização identitária, no caso, a obrigação de afirmação e perpetuação da raça.
} 
uma concepção de solidariedade que depende de diferenças radicais e que insiste em relações de interdependência incomensurável, como discutirei na próxima seção.

No ponto central da crítica de Bayertz ao termo, está a tensão entre se a solidariedade é um "predicado factual" que descreve aspectos particulares da interação social e/ou política humana, ou uma "determinação metafísica" que prescreve o que essas interações poderiam ou deveriam implicar:

"Solidariedade" é agora compreendida como um apego mútuo entre indivíduos, abrangendo dois níveis: um nível factual de terreno comum entre os indivíduos e um nível normativo de obrigações mútuas de ajudar um ao outro, como e quando necessário (BAYERTZ, 1999, p. 2, itálico original).

Para Bayertz, os dois objetivos do conceito estão intimamente relacionados, como aqueles que usam o conceito de solidariedade de maneira descritiva o fazem em busca de padrões que possam produzir normas prescritivas, para abordar problemas sociais ou políticos. Isso é verdade, independente do contexto político em que o conceito está sendo mobilizado.

Se de forma descritiva ou prescritiva, a solidariedade pode se referir às relações sociais em diferentes níveis de abstração, do universalista ao interpessoal, incluindo os tipos de solidariedade social, cívica e política. Bayertz (1999) propõe quatro usos diferentes do termo em relação à moralidade (solidariedade humana), sociedade (solidariedade social), libertação (solidariedade política) e estado de bem-estar social (solidariedade cívica) e demonstra, astutamente, tanto as premissas quanto as limitações desses quatro usos do termo. Ele argumenta, por exemplo, que a solidariedade humana se baseia em uma comunidade moral humana idealizada, que não leva em conta, adequadamente, "sentimentos e ações anti solidárias" entre pessoas humanas (p. 7). A solidariedade cívica, como característica do estado de bem-estar social, embora baseada no princípio moral da responsabilidade compartilhada pelo bem-estar coletivo, também opera através de uma forma de coerção institucionalizada. O que a análise de Bayertz revela, são as maneiras pelas quais as noções de solidariedade são capturadas nas concepções de humanidade, cidadania, pertencimento social e obrigação moral. Esses são os mesmos conceitos em torno dos quais a colonização e outras dinâmicas de opressão também operam, apontando que a solidariedade sempre opera em tensão com as lógicas de dominação.

O conceito de solidariedade em relação a um senso de responsabilidade mútua e moral tem raízes teológicas, que podem ser mapeadas em relação à maioria das religiões do mundo. Todas as principais religiões do mundo atribuem grande importância a alguma ideia que implica responsabilidade de uns os outros, particularmente para os que são vistos como desfavorecidos ou de 
alguma forma privados de algo ${ }^{12} \mathrm{O}$ solidariedade também está ligado aos ensinamentos da Regra de Ouro, ou "ética da reciprocidade", algo também expresso em muitas religiões do mundo. À medida que evoluiu na Europa durante os séculos XVIII e XIX, a solidariedade está intimamente ligada ao cristianismo, e ao conceito de caritas (nota do tradutor - do latim, caridade), em particular (BAYERTZ, 1999; SCHOLZ, 2008; STJERNØ, 2005). ${ }^{13}$ Isso é importante porque implica noções de solidariedade como parte da justificação para a conversão religiosa, como estratégia central para a colonização. $^{14}$

Michael Hoelzl argumenta, na verdade, que o desafio central para a ciência social crítica de dar um significado para solidariedade, é que "ela não pode ser totalmente explicada sem considerar sua dimensão teológica implícita" (2005, p. 46). Isso é particularmente verdadeiro no caso de atos assimétricos de solidariedade, que "desafiam uma teoria baseada na normatividade de formas recíprocas de reconhecimento" (p. 49), como é o caso das teorias de coesão social que estão embutidas na evolução do Estado Nação.

O ímpeto por trás da busca de normas para garantir a coesão social, remonta ao trabalho do cientista social islâmico do século XIV, Ibn Khaldūn (1332-1406), e seu conceito de asabiyah (IBN KHALDŪN, 2005) $)^{15}$. Evoluiu através dos trabalhos de sociólogos europeus do século XIX como August Comte, Ferdinand Tönnies e Emile Durkheim, na tentativa de definir os padrões que garantiriam a coesão social e a solidariedade entre os membros da sociedade europeia, cada vez mais

\footnotetext{
12 Por exemplo: no Islã, "zakat” é um dos cinco pilares que formam a base da adoração; no judaísmo, "tsedacá" é considerado uma obrigação religiosa; no hinduísmo, "dana" é o terceiro dos dez "Niyamas" ou práticas. Todas essas práticas envolvem alguma forma de obrigação para com os outros em circunstâncias menores.

${ }^{13}$ Como observa Scholz (2008), "a solidariedade aparece durante todo o Ensino Social Católico, a partir de meados do século XX, como um dos princípios primários. Aplica-se a indivíduos e nações como uma obrigação de ajudar os necessitados, com ênfase especial no desenvolvimento humano completo - desenvolvimento educacional, religioso e social, além de econômico" (p. 7). Em sua história do conceito, Steinar Stjernø (2005) observa que para os católicos e protestantes, ideias de solidariedade "são baseadas na crença de que o homem é criado à imagem de Deus e que todo ser humano é igual aos olhos de Deus. O ensino social católico, que é mais explícito, enfatiza a interdependência humana e a família. Os protestantes mais frequentemente, mencionam o dever cristão de servir a outros seres humanos"(p. 88).

${ }^{14}$ De fato, foi um senso de obrigação solidária com os povos indígenas do Caribe, baseado na possibilidade de sua conversão ao cristianismo, que levou Bartolomé de las Casas a defender seu status de seres humanos (Wynter, 2003).

${ }^{15}$ No Muqaddimah, Khaldūn (2005) oferece uma análise do senso compartilhado de coesão entre grupos nômades no norte da África. Ele observou os laços fortes, correspondentes ao senso de parentesco entre parentes sanguíneos que caracterizavam laços entre pessoas que coexistiam ou se envolviam através de atividades diárias. Essa análise corresponde ao que Emile Durkheim (1933) mais tarde chamou de "solidariedade mecânica", diferenciado dos tipos de formas despersonalizadas e individualizadas de coesão social, característica da sociedade industrializada que ele chamou de "solidariedade orgânica". Para Durkheim, a crescente diferenciação e individuação de papéis dentro da divisão do trabalho na sociedade moderna, produziram um modo de coesão social menos dependente do parentesco e da semelhança social e mais da função de papéis diferenciados.
} 
industrializada. Os teóricos contemporâneos da solidariedade social preocupam-se com a questão de saber se a coesão social nos Estados Nações modernos se baseia em sentimentos de mutualidade ou é um acordo de "benefício comum" baseado no interesse racional (BAYERTZ, 1999; CROW, 2002). Está em jogo, é claro, a questão da inclusão e quem conta como membro da unidade social a quem são devidas tais obrigações solidárias. No que se refere às normas e obrigações morais, o conceito de solidariedade social faz mais pelo cumprimento das ordens coloniais do que pela descolonização. Isso também se aplica às concepções normativas de solidariedade política.

Hoelzl (2005) descreve o surgimento do conceito de solidariedade política no contexto da Revolução Francesa. Do adjetivo latino in solidum - para o todo - a palavra solidarité, surge primeiro como uma reação conservadora, que buscava afirmar a autoridade do monarca como o soberano de uma ordem social divina à qual todo indivíduo ou devia uma dívida coletiva ou uma obrigação solidária. ${ }^{16} \mathrm{O}$ significado de solidariedade foi mais tarde liberalizado, afastando-se da noção de uma dívida com Deus em relação à responsabilidade consigo e com o outro. O filósofo Pierre Leroux, pai do socialismo francês, usa especificamente o termo solidarité humaine como "uma lei natural de solidariedade que estipula um direito de proteção existencial da comunidade para todos os indivíduos, com base não nas relações emocionais entre os indivíduos, mas na ideia de igualdade" (OTTMAN, 2008, p. 39, itálico original). A solidariedade torna-se então, central para os movimentos sociais do século XIX, particularmente, para a evolução da Comuna de Paris, a Primeira Internacional e o surgimento de um movimento internacional de trabalhadores.

É neste contexto, que uma teorização da solidariedade nas ciências políticas e sociais muda o foco da coesão social, para um foco nos interesses do grupo e na luta política. Particularmente no trabalho de Karl Marx e Friedrich Engels (1967), e mais tarde Max Weber (1946), a solidariedade surge como uma qualidade de relacionamento entre grupos particulares de pessoas, com interesses compartilhados, e não com a sociedade como um todo. Nesse caso, a solidariedade "denota a coesão emocional entre os membros desses movimentos sociais e o apoio mútuo que eles dão um ao outro na batalha por objetivos comuns" (BAYERTZ, 1999, p. 16). Crucial para a solidariedade política, é a identificação de um oponente contra o qual as lutas devem ser travadas, para se alcançar objetivos específicos. Isto significa que é ao mesmo tempo contraditório e exclusivo, revelando as dimensões morais que sempre acompanham as reivindicações de solidariedade política. Isto também aponta para o fato de que as relações solidárias, podem ser mobilizadas para diversos objetivos políticos, relativos

\footnotetext{
${ }^{16}$ Segundo Ottman, "originalmente, solidariedade era um conceito puramente legal. No direito civil romano, o obrigatio in solidum se refere à responsabilidade solidária de múltiplos credores ou devedores” (2008, p. 38).
} 
aos interesses de grupos específicos, incluindo extremistas de toda persuasão ideológica. Como argumentam Scholz (2008) e Bayertz (1999), a solidariedade política também implica um risco ou mesmo, a vontade de se fazer um sacrifício pela causa da justiça. A extensão desse sacrifício ou aquilo que importa como risco razoável está, é claro, sujeita a debate, e aponta para as maneiras pelas quais a solidariedade parece sempre exigir o que Hoelzl (2005) chama de "referente transcendente", através do qual na ausência de Deus, determinações de sacrifício podem ser feitas.

Observando que a solidariedade permanece como um conceito difuso, usado em relação a uma infinidade de problemas sociais e relações complexas, Crow observa que o conceito evoluiu no século XIX, durante "um período de transformação em que os arranjos sociais tradicionais estavam sendo reformulados" (2002, p. 27). Ele argumenta que processos divergentes "como secularização, urbanização, democratização, desenvolvimento do estado moderno e desenvolvimento do capitalismo", formataram o desenvolvimento de diferentes ideias sobre solidariedade (p. 28). Eu acrescentaria, que a solidariedade social e política evoluiu no contexto da expansão colonial e também, serviu para articular a centralidade da metrópole imperial tanto como local de coesão social quanto luta política.

Steinar Stjernø (2005) aponta que mudanças semelhantes hoje, exigem um envolvimento cuidadoso com o conceito. "Na era do individualismo", ele argumenta, "a ideia de solidariedade parece estar ameaçada e na defensiva. O triunfo do capitalismo e a expansão dos mercados e da ideologia do mercado, tornam mais precários os arranjos coletivos e as ideias sobre as quais se baseiam" (p.2). Alguns cientistas sociais continuaram a examinar o papel da solidariedade na sociedade contemporânea, desenvolvendo respostas ao aumento do individualismo e algo que alguns veem como uma fratura das relações sociais, que tende a minar as relações solidárias (BAUMAN, 2008; BECK, 1997; CALHOUN, 2006; SENNETT, 1998). Crow (2002) argumenta, que há muitas divergências quanto ao grau em que as relações sociais contemporâneas são caracterizadas por uma ruptura com o passado, juntamente com modos anteriores de solidariedade ou pela continuidade com o passado, juntamente com uma reafirmação de ligações solidárias.

O potencial da solidariedade como resposta descolonizadora às condições presentes, no entanto, não consiste em tentar descobrir se/e como os grupos sociais se organizam para proteger os interesses de seus membros. De fato, embora seja crucial reconhecer a genealogia descrita brevemente acima, entender a solidariedade em relação à coesão social ou como fonte de ação coletiva para grupos em competição entre si, tem o efeito de reproduzir a lógica colonizadora das ciências sociais europeias tanto clássicas, quanto contemporâneas. Uma pedagogia descolonizadora da solidariedade deve desviar o foco da explicação ou do aprimoramento dos arranjos sociais 
existentes, procurando desafiar esses arranjos e sua lógica colonial implícita. Em particular, a solidariedade em relação à descolonização é desafiar a própria ideia do que significa ser uma pessoa humana e, por extensão, as lógicas de inclusão e exclusão que impõem limites sociais, incluindo noções de solidariedade social, política e cívica. Trata-se de imaginar relações humanas baseadas na relação entre diferença e interdependência, em vez de semelhança e cálculo racional de interesses próprios.

Isso não significa que a teorização prévia da solidariedade não seja útil, ao contrário. Embora difusa, a solidariedade não aceita todas e quaisquer definições, e a tarefa de definir o que entendemos por uma solidariedade descolonizadora, exige uma consideração de exames prévios e das muitas perguntas que ela revela, sobre o que exatamente está vinculado à solidariedade. A solidariedade exige, mesmo desafiando, herdar categorias políticas e sociais? A solidariedade exige semelhança, interesses compartilhados ou um destino comum, ou pode funcionar em um contexto comprometido com uma interdependência incomensurável? A solidariedade implica uma relação hierárquica entre os que são solidários ou contra os que são alvo da atividade solidária? A solidariedade depende de uma moralidade específica ou pode existir no contexto de reivindicações morais diferentes, talvez até opostas?

Embora diferentes maneiras de entender a solidariedade sugiram respostas diferentes para estas perguntas, há pelo menos três coisas que todas as expressões do conceito compartilham. Primeiro, a solidariedade sempre implica um relacionamento entre indivíduos ou grupos, seja como uma maneira de entender o que une as pessoas seja para a ação cívica ou política. Segundo, a solidariedade sempre implica uma obrigação, ou um senso de dever em relação ao que é justo ou equitativo, e que seja interpretado em relação à alguma noção de direitos humanos, contrato social ou compromissos de lutas contra formas particulares de opressão. Terceiro, a solidariedade sempre implica em um conjunto de ações ou deveres, entre os que estão no relacionamento solidário, desde a disposição de tratar os outros como se gostaria de ser tratado, até o tipo de sacrifício de vida que Hoelzl (2005) teoriza como o caso limite da solidariedade assimétrica. Com base nessas três observações, quero propor uma maneira de pensar a solidariedade, especificamente, em relação à educação anti opressiva e aos projetos de descolonização que levam a sério as condições e implicações do momento presente. Através da pedagogia da solidariedade, busco reimaginar, uma vez mais, as condições para encontros éticos com outros, que desafiem as condições atuais de colonização e desigualdade.

Como meu foco aqui é a pedagogia como uma forma de política, detenho-me principalmente no trabalho de acadêmicas que teorizaram as várias formas de solidariedade política, particularmente 
o trabalho de acadêmicas feministas como Audre Lorde (1984), Jodi Dean (1996), Iris Marion Young (2002), Chela Sandoval (2000), Sara Ahmed (2000) e Chandra Mohanty (2003). Estas intelectuais dedicaram muitas páginas a repensar a solidariedade, propondo maneiras pelas quais ela abre as portas para imaginar as relações humanas de maneira diferente. No "Feminismo sem Fronteiras", por exemplo, Chandra Mohanty descreve a solidariedade "como base para as relações entre diversas comunidades [nas quais] diversidade e diferença são valores centrais" (2003, p. 7). Ela convida a repensar a solidariedade feminista como constituindo "a maneira mais baseada em princípios de atravessar fronteiras - descolonizar o conhecimento e praticar a crítica anticapitalista" (p. 7). É através destes trabalhos, juntamente com outros que teorizaram a descolonização e a educação anti opressora, que ofereço os três modos de "pedagogia da solidariedade" a seguir.

\section{TRÊS MODOS PARA UMA PEDAGOGIA DA SOLIDARIEDADE}

Antes de prosseguir, é importante esclarecer a mudança para a pedagogia e articular brevemente os parâmetros pelos quais uso o termo aqui. Em contraste com o termo currículo, que se concentra na relação entre indivíduo e conhecimento/conhecer, a pedagogia destaca o caráter relacional e o objetivo de todos os projetos educacionais; a pedagogia "é inerentemente diretiva e deve sempre ser transformadora" (MACEDO, 2005, p. 25). Além disso, uma crítica indígena ao currículo destaca as maneiras pelas quais o imperativo curricular de "incluir" sempre tem os efeitos de delimitar tanto o conhecimento indígena (RICHARDSON, 2011), quanto substituir suas instituições (TUCK, GAZTAMBIDE-FERNÁNDEZ, no prelo). Portanto, a pedagogia da solidariedade articulada aqui carrega um compromisso, sem desculpas, com objetivos antirracistas e descolonizadores.

O currículo, como o cosmopolitismo, é direcionado para o eu; trata-se do que o indivíduo deve saber, ser capaz de fazer ou compreender as experiências individuais e estimular uma orientação individual em relação à diferença. Em vez disso, como a solidariedade, a pedagogia é direcionada para o relacional e destaca o processo pelo qual somos feitos pelos outros através da diferença e para ela. A pedagogia ocorre em um encontro entre sujeitos, que também são feitos - e, portanto, transformados - no e através do encontro como sujeitos. A pedagogia, portanto, está voltada para a ética, pois representa a "violência que acompanha a própria constituição da subjetividade" (TODD, 2001, p. 431).

Essa virada ética compreende o encontro pedagógico como um processo através do qual professor e o aprendiz são transformados, para o qual ambos trazem algo e do qual, também absorvem 
ao mesmo tempo (TODD, 2001). Uma virada ética na pedagogia ressalta a imprevisibilidade do encontro e a coerção inerente ao processo de "aprender para tornar-se". Para Sharon Todd,

Professores, como veículos através dos quais a demanda pedagógica de "aprender a se tornar" se torna real para os alunos, não podem escapar de seu papel - exigem que os alunos se prendam a apegos e significados simbólicos ao currículos que apresentam e ao fazê-lo, não podem escapar de um certo grau de coerção. ... É precisamente porque a violência é inerente ao "aprender a se tornar" e porque professores e alunos são continuamente vulneráveis um ao outro diante dessa violência, que a questão da não violência pode até ser levantada. (2001, pp. 438-439)

A coerção no processo de "aprender a se tornar" fica ainda mais violenta quando a tarefa é desafiar - transformar - as subjetividades herdadas e continuamente produzidas por processos contínuos de colonização. O tipo de "herança difícil" que uma pedagogia comprometida com a descolonização e o antirracismo pode trazer à tona "está ligada ao problema ético de aprender a explicar de maneira imaginativa as formas de vida que ela deixa em ruínas" (TARC, 2011, p. 16)

Para essa tarefa, a pedagogia da solidariedade compromete-se com três modos de trabalho solidário enredados em sua formação, cada um dos quais pode ser descrito como um aspecto ou um tipo de solidariedade: relacional, transitiva e criativa.

\section{SOLIDARIEDADE RELACIONAL}

Se todas as concepções de solidariedade se apresentam em algum tipo de relacionamento; e a pedagogia é sempre relacional, pode parecer excessivamente redundante chamar a pedagogia da solidariedade de relacional; a redundância é deliberada. Falar da pedagogia da solidariedade como relacional é assumir um compromisso deliberado à uma postura relacional. Como argumenta Jody Dean (1996), tal "compromisso deliberado com a reciprocidade" nos lembra que a solidariedade em condições pós-modernas deve ser alcançada” (p. 46, itálico adicionado). Ao contrário das formas de solidariedade que parecem emergir da "natureza" de um relacionamento, familiar ou comunitário, Dean (1996) propõe uma concepção mais abstrata de solidariedade "reflexiva" para destacar um compromisso deliberado. ${ }^{17}$ Pensar na pedagogia da solidariedade como relacional é, em primeiro lugar, reconhecer a copresença, tomando deliberadamente como ponto de partida que sujeitos na sua individualidade não entram em relacionamentos, mas em vez disso são feitos nos e através dos relacionamentos.

\footnotetext{
${ }^{17}$ Dean (1996) faz uma distinção entre solidariedade reflexiva e o que ela chama de "afetiva" (baseada no parentesco e nos laços familiares) e "convencional" (baseada em interesses e preocupações comuns).
} 
A aparente separação ou distância do outro, é onde Jean-Luc Nancy identificou a ilusão da individualidade que impregna o sujeito moderno. Não somos quem ou aquilo que pensamos ser fora dos relacionamentos; é nestes relacionamentos que somos feitos como sujeitos, não existe um $e u$ fora de nós e não existe um nós sem um eles. Nancy (2000) desenvolve esta ideia em seu ensaio "Sendo Singular (no) Plural" (tradução livre), no qual ele ressalta primeiro, que o ser é sempre um "estar com", e, que não existe existência fora de uma coexistência. O que é mais convincente no argumento de Nancy, e que ele também desenvolve em seu ensaio "A Comunidade Inoperante" (tradução livre) (1991), é que o coletivo implícito em "ser" nunca é uma entidade já definida, com marcadores estáveis de qualquer tipo. Em vez disso, nosso ser coletivo também é um ser em relação a outro, com limites que são parte integrante do ser e que são constantemente negociados, redefinidos, invadidos e ampliados. Nancy fornece um ponto de partida para uma concepção da pessoa humana que se baseia, não na salvação do pecado (teológica) ou na razão individual (racional), mas na interdependência (relacional). ${ }^{18}$

Tomando a noção de estar-com no ponto de partida a questão se torna então, como manter relacionamentos baseados em um compromisso solidário com os outros, e através dos quais o eu é constituído, com a mudança das condições econômicas e das ordens simbólicas através da qual o eu e o outro são constituídos como tal. Não se trata tanto de conhecer o outro, pois o outro é, segundo Levinas, "infinitamente incognoscível”, mas sim, atender às condições de possibilidade que produzem o encontro entre o eu e o outro (Todd, 2001). Para Sara Ahmed, isso requer estar atento às condições do encontro que "podem afetar para onde ainda estamos indo" (2000, p. 145, itálico original):

Descrever, não o outro, mas o modo de encontro em que me deparo com outro, é, portanto, não manter o outro no lugar, ou transformá-lo em um tema, conceito ou coisa. Pelo contrário, é dar conta das condições de possibilidade de ser encarada por ela de tal maneira que ela deixe de estar plenamente presente neste exato momento do face a face, uma não presença que, ao mesmo tempo abre a possibilidade de enfrentar algo diferente desse outro, de algo que pode surpreender quem está enfrentando e aquele a que se enfrenta (o 'ainda não' e 'o outro'). (p. 145)

\footnotetext{
${ }^{18}$ Embora ele não leve em conta a terra ou a natureza, é importante notar que as visões de Nancy são consistentes com as estruturas indígenas nas quais, como explicam Amadahy e Lawrence (2009): "indivíduos não existem e não poderiam existir fora da comunidade ou da terra. Nosso relacionamento passado, presente e futuro define quem somos e determinamos quais papéis desempenhamos, bem como responsabilidades que temos para com a comunidade e a terra que a sustenta. Da mesma forma, quem somos e o que fazemos como indivíduos afeta esse amplo senso de comunidade". (p. 117)
} 
Pensar na solidariedade de forma relacional é fazer a pergunta: como estou sendo criado por outros? Quais são as consequências do meu ser nos outros? Que tipo de sacrifícios estão implícitos na mitologia de mim mesmo como ser e na minha insistência em minha liberdade individual? Tratase, em última análise, examinar os arranjos específicos que permitem que as subjetividades surjam e sejam constituídas como experiências individuais. Essa maneira de questionar o "ser" traz para o centro condições materiais e destaca a desigualdade como base do ser presente, e não como um acidente das condições presentes. Também destaca o "duplo vínculo" de reconhecer e, ao mesmo tempo, prejudicar as próprias construções de diferença que tornam os relacionamentos e, portanto, o sujeito, inteligíveis (SPIVAK, 1999). Enfrentar ser desta maneira significa perguntar como esta mitologia de mim é o resultado de circunstâncias desiguais e injustiça; trata-se fundamentalmente, ao mesmo tempo, da política de identidade, assim como a política de imaginar um futuro.

Em seu livro "Inclusão e Democracia", Iris Marion Young argumenta convincentemente por uma solidariedade diferenciada que "percebe e afirma que grupos diferenciados local e culturalmente convivam juntos em uma região mais ampla, cujas condições estruturais e ambientais afetam a todos, e onde a ação e a interação geralmente têm consequências distributivas que tendem a beneficiar alguns sobre outros" (2002, p. 197). Para Young, a tarefa da política é abordar a desigualdade estrutural, a fim de garantir a participação plena daqueles que estão em posições diferentes na sociedade. Young abraça a política da diferença, rejeitando a alegação de que ela constitui um enfraquecimento da democracia deliberativa e um compromisso com o bem comum. No entanto, para Young, nem todas as diferenças contam, e somente aquelas que são o resultado da injustiça e da desigualdade estrutural devem ser levadas a efeito na tomada de um julgamento sobre o que é justo. Young sustenta que um processo de deliberação racional deve diferenciar entre "interesses paroquiais" e diferenças sociais politicamente significativas.

O que Young não consegue conciliar é que, para aqueles a quem a desigualdade estrutural posicionou como "diferente", a distinção entre paroquial e político está enredada no confuso nó entre o que Linda Alcoff (2000) chama de "identidade pública" (o que Young pode reconhecer como diferença social) e sua subjetividade, ou "meu próprio senso de mim" (o que Young poderia descartar como paroquial). Young comete o erro que Alcoff atribui ao senso comum ocidental de pensar "que temos mais controle individual sobre nossa subjetividade do que sobre nossa identidade pública" (2000, p. 336). Esse erro é o resultado do sujeito idealizado implícito de Young, para quem a identidade e a subjetividade públicas não estão em desacordo significativo e que podem presumivelmente entrar no espaço deliberativo livre do interesse paroquial e pronto para se envolver no argumento racional. 
Mais do que o sujeito idealizado, uma solidariedade relacional comprometida com a descolonização toma a experiência da colonização e do outro racializado como ponto de partida. É o espaço em que o subalterno pode falar, que vem da "dupla consciência" de W.E.B Du Bois (1961), à "ligação dupla" de Gayatri Spivak (1999), até o que Frantz Fanon chamou de "maldição corporal", o desequilíbrio de tomar consciência do corpo de alguém "em uma pessoa tripla", aprisionado no olhar do homem branco (1967, p. 84):

O que mais poderia ser para mim senão uma amputação, uma excisão, uma hemorragia que salpicava todo o meu corpo com sangue negro? Mas eu não queria essa revisão, essa tematização. Tudo que eu queria era ser um homem entre outros homens. Eu queria tornar-me flexível e jovem em um mundo que fosse nosso e ajudar a construílo juntos. (FANON, 1967, p. 85)

\section{SOLIDARIEDADE TRANSITIVA}

Solidarizarse ${ }^{19}$. Mais comum em idiomas românicos do que em inglês, a forma verbal de solidariedade - solidarizar-se com - é um verbo transitivo. Freire sugere isso quando define solidariedade, como um ato de entrar em uma relação solidária com os outros:

A solidariedade exige que alguém entre na situação daqueles com quem é solidário; é uma postura radical ... a verdadeira solidariedade com os oprimidos significa lutar ao seu lado para transformar a realidade objetiva que os tornou esses "seres para outro". (1970, p. 49)

Certamente, parte do que distingue a solidariedade de outras estratégias de coalizão e maneiras de conceituar as relações humanas de maneira mais geral, é que ela aponta diretamente para uma orientação ativa em relação aos outros que, em sua própria transitividade, rejeita uma posição estática e abraça a contingência. Nesse sentido, é crucial entender a pedagogia da solidariedade como um termo de engajamento - como uma praxis.

A pedagogia da solidariedade não é simplesmente entrar em um estado de solidariedade estar em solidariedade - o que pode sugerir sentimentos para alguém, mas sim como ações tomadas em relação a alguém. Mais importante, talvez, a pedagogia da solidariedade se refira a uma ação que também afeta ou modifica quem age - para solidarizar-se com. É a voz do meio, na qual a ação do verbo não é direcionada apenas para outro, mas também modifica o sujeito que a executa (SANDOVAL, 2000). Solidarizar-se é sobre uma performance que transforma intérprete e público e, portanto, tem o potencial de subverter a linguagem e suas funções ideológicas (BUTLER, 1997). Nesse sentido, uma pedagogia da solidariedade se opõe a expressões comuns de solidariedade, que

\footnotetext{
${ }^{19}$ N. da RT: mantivemos a expressão na forma, em espanhol, que aparece originalmente no artigo em inglês.
} 
trabalham em grande parte para exaltar e exonerar ou ignorar a cumplicidade na colonização em andamento. Rejeita o tipo de pseudo solidariedade do "humanitarismo de celebridade" que se torna o que Lilie Chouliaraki descreve como "uma prática do altruísmo voyeurístico [que] reproduz a distância moral entre 'nós' e 'eles'" (2011, p. 366). Em vez disso, a transitividade da pedagogia da solidariedade envolve o que Chela Sandoval chama de modo diferencial de consciência, que conscientemente implanta - e transforma - a subjetividade:

A implantação de uma ação que recria o agente, até quando o agente está criando a ação - em um ciclo de transformação quiasmático contínuo. A ativista diferencial é assim feita pela intervenção ideológica que ela também está fazendo: o único resultado final previsível é a própria transformação. (2000, p. 157)

Por buscar permanentemente a transformação, a solidariedade transitiva é frágil e, por definição, acidental. A solidariedade transitiva se opõe a uma concepção de solidariedade baseada em algum tipo de essência humana, que falha desde o início porque exclui por padrão e opera na rejeição da diferença a priori de todos os encontros (RORTY, 1989). "O que conta como um ser humano decente", diz Rorty, é "uma questão de consenso transitório sobre quais atitudes são normais e que práticas são justas ou injustas"(p. 189). Rorty argumenta que a contingência é uma condição necessária para manter um senso de solidariedade.

Ao mesmo tempo, a transitividade se opõe ao tipo de "solidariedade irônica" baseada na concepção de contingência de Rorty (1989), na qual a solidariedade se torna "uma questão de auto empoderamento", através da qual o sujeito ocidental idealizado aprimora sua humanidade, às custas do sofrimento de outras pessoas, através da prática da "cumplicidade postergada" (GAZTAMBIDEFERNÁNDEZ, 2009; RAZACK, 1998). As questões que a transitividade sugere têm a ver com nossa disposição de agir no mundo, usando as famosas palavras de Stuart Hall (1986), "sem garantias". Que resultados inimagináveis e inimaginados poderiam se tornar disponíveis se estivéssemos dispostos a arriscar a possibilidade de, simplesmente, não saber para onde estamos indo? Ou pior ainda, que essa mitologia minha, na qual meu senso de autoconfiança se baseia, é exposta pelo que é - uma mitologia - e substituída por alguma outra mitologia necessária e transitória? Investimos tanto nos resultados que imaginamos de nossas ações, que isso parece nos colocar em uma posição precária como supostos agentes.

A compreensão de que todo ser é contingente, gera uma certa ansiedade que se tornou paralisante, principalmente para aqueles de nós da academia que se interessam tanto pelas várias mitologias de quem somos e do que afirmamos fazer. Tenho tanto medo de reconhecer os privilégios presumidos em minha mitologia em particular, que muitas vezes me iludo pensando que meu trabalho faz a diferença, mesmo quando é totalmente claro que não. Ou procuro equilibrar esses privilégios 
com uma mitologia paralela de inocência, que me faz sentir melhor comigo mesmo, enquanto minha capacidade de mobilizar essa narrativa presume um tipo particular (desigualmente distribuído e às vezes precário) de privilégio acadêmico.

Mas essa percepção pode levar a uma paralisia grosseira que não levará a mudanças sociais. Esta é a razão pela qual a solidariedade transitiva insiste na práxis; pensar na solidariedade como um verbo transitivo, significa sublinhar que exige que ajamos no mundo. E, é claro, essa atuação no mundo pressupõe a noção de práxis desenvolvida por Freire (1970), uma atuação no mundo que é informada por pensar sobre o mundo e refletir sobre a ação e, é claro, refletir como ação. Aqui, quero voltar a Sandoval (2000), porque ela elabora um tipo particular de atuação no mundo, com base na noção de consciência diferencial e também oferece suas ideias como uma resposta à paralisia, especificamente o tipo de paralisia que emerge da crítica de Fredric Jameson (1984) ao pós-moderno, como uma espécie de beco sem saída do modernismo.

Para Sandoval, movimentos sociais diferenciados - como a pedagogia da solidariedade aqui apresentada - envolvem um tipo de práxis social que intervém no aparato ideológico pelo qual o poder é implantado. Agindo com e contra os arranjos simbólicos de que o poder dispõe, como "identidades" e "culturas", "os praticantes podem se substituir conscientemente dentro do círculo de concepções morais que definem nossos horizontes sociais atuais, pois sua atividade desfaz a consciência - a encarnação da lei - renovando, assim, a própria consciência” (2000, p. 178).

Essa ideia de solidariedade como práxis, ou mais precisamente de solidariedade como manifestação de consciência diferencial, levanta questões adicionais. Como realmente sabemos se e como nossas ações levam a algum tipo de reconfiguração de ideias ou reestruturação da desigualdade? Como saberíamos a diferença? Que tipos de novas mitologias do eu estão à espreita por trás do que decidimos fazer e como decidimos continuar no mundo? Será que estou realmente disposto a agir de uma maneira que possa frustrar minha mitologia sobre mim? "O que deve ser lembrado", insiste Sandoval, "é que o diferencial reside no lugar em que o significado escapa a qualquer ponto de ancoragem final, escapando para surpreender ou aconchegar-se nos contornos móveis do poder - é parte integrante do significado indefinível que constantemente escapa toda análise" (2000, p. 179).

\section{SOLIDARIEDADE CRIATIVA}

A poesia é a maneira pela qual ajudamos a dar nome ao que não tem nome, para que possa ser pensado. Os horizontes externos mais distantes de nossas esperanças e 
medos são cobertos por nossos poemas, esculpidos nas experiências rupestres de nossas vidas diárias. (LORDE, 1984, p. 37)

Como a consciência diferencial de Sandoval, a pedagogia da solidariedade "está ligada ao que não se expressa por meio de palavras. É acessado através de modos poéticos de expressão: gestos, músicas, imagens, sons, palavras, que despencam ou se elevam através da significação para encontrar algum vazio - algum 'não lugar' - para reivindicar o que lhes é devido" (2000, p. 149). Isso é especialmente importante quando tentamos repensar os encontros com outras pessoas, de maneira a reorganizar as ordens simbólicas hierárquicas que produzem as mesmas diferenças que tornam esses encontros legíveis. Isso envolve o engajamento "criativo" com os outros de maneiras inesperadas e, talvez, até inoportunas que possam reorganizar o conteúdo simbólico das trocas humanas, mobilizando aquilo que sempre excede os próprios termos do encontro. Requer o enfrentamento da "hegemonia nas fibras do eu e na substância dura prática dos relacionamentos efetivos e contínuos" (WILLIAMS, 1977, p. 212).

O termo "criativo" carrega suas próprias complicações conceituais, pois é tipicamente enquadrado nos limites de um sujeito que se presume criativo ou ter capacidade de criatividade. Talvez porque a história conceitual da "criatividade" tenha sido predominantemente localizada na psicologia e, mais recentemente, na psicologia social, o conceito é construído sobre ideias de individualidade, que se chocam contra as premissas da solidariedade relacional e transitiva. Mesmo o tipo de abordagem interdisciplinar defendida por estudiosos, que reconhecem as formas complexas em que a criatividade está situada em contextos sociais e culturais, mantém uma concepção do "indivíduo criativo" que entra em processos criativos coletivos com o objetivo de aprimorar as habilidades individuais (SAWYER, DEZUTTER, 2009; SAWYER, 2012). O mesmo atomismo psicologizante, evidente nas versões individualistas da criatividade permeia a abordagem sociocultural, na qual indivíduos presumivelmente racionais (e, é claro, criativos) contribuem com suas perspectivas únicas para a melhoria do processo criativo.

Falta em tal visão uma consideração do contexto mais amplo de lutas por significado, e, como os recursos simbólicos e econômicos são entrelaçados e circulam por meio de desigualdades estruturais. No entanto, como Paul Willis $(1990 ; 1998)$ nos lembra, é através do trabalho simbólico e da criatividade que nos envolvemos com o senso de coletividade que estrutura a individualidade, chegando a um acordo com as restrições materiais e simbólicas que estruturam o eu. O conceito de "estética fundamentada" de Willis tem como premissa uma concepção intersubjetiva de criatividade que é consistente com a solidariedade relacional: "É através do conhecimento do "outro", incluindo 
reconhecer o 'eu' como um 'outro' por alguns outros, que um 'eu e outros" podem ser conhecidos absolutamente (1990, p. 12). Obviamente, nem todos os outros também são "o Outro" ou são constituídos como "o estranho", como Ahmed (2000) nos lembra; aqui, de novo, é crucial centralizar as experiências daqueles que não são apenas outros, mas "Outros" em como entendemos a solidariedade criativa. Willis não é ingênuo à esta dinâmica de poder, como costuma ser a maioria dos teóricos da criatividade, mas se recusa a abandonar a possibilidade de novos arranjos por meio do jogo simbólico. "Associações de raça, classe, gênero, idade e região não são apenas aprendidas, são vividas e experimentadas. Isto é assim, mesmo que apenas empurrando contra os limites opressivos da ordem e do poder estabelecidos" (1990, p. 12).

Se a solidariedade relacional exige uma ontologia diferente e uma solidariedade transitória, um novo tipo de práxis, a solidariedade criativa deve insistir em uma concepção de cultura mais complexa e mais precisa, do que a que informa o multiculturalismo e mesmo o cosmopolitismo. Em vez de um local de coerência e unidade, a solidariedade criativa requer uma visão da cultura como um local de ação, mudança e dissonância, rejeitando a visão dominante da cultura como algo inerente a quem somos ou algo que podemos afirmar autenticamente possuir, com limites estáveis e fixos. Tal visão da cultura abandonaria necessariamente qualquer noção que implicaria a existência de culturas "múltiplas". Em vez disso, como o colonialismo e a modernidade, existem várias maneiras e espaços em que a cultura é produzida, reproduzida e resistida, implicando diferentes arranjos simbólicos que não são distintamente separados de outros arranjos, mas são extensões e manifestação de aspectos sociais maiores, sejam eles arranjos econômicos, sociais e políticos e mesmo culturais.

O que proponho como central para a solidariedade criativa, é uma espécie de pósculturalismo, não porque superamos a cultura como uma ideia ou um conceito, mas porque insistimos na ideia de cultura como sempre imanente. O termo "pós" não é uma evocação que reivindica algum tipo de avanço, mas, seguindo a teoria pós-colonial, "pós” convida a um envolvimento direto com a crítica da cultura como uma parte sempre presente e em constante mudança de como se envolver através da diferença. Não estou sugerindo que devemos abandonar o conceito de cultura como algo que os antropólogos inventaram para que eles pudessem ter um papel na conquista colonial, mas sim que nos envolvamos na análise da cultura como algo que fazemos e que nos é feito, através dos vários arranjos simbólicos que organizam as relações humanas. A cultura é o desenlace de um encontro entre sujeitos, negociando criativamente - e às vezes reorganizando - as condições estruturais que produzem o encontro, em primeiro lugar.

A pedagogia da solidariedade preocupa-se com as condições de possibilidade de encontros éticos, que reorganizam as condições estruturais incluindo as dimensões simbólica e material que 
produzem o encontro. Os encontros com as diferenças - e eu argumentaria, seguindo Ahmed (2000), que todos os encontros são encontros com diferenças que sempre são hierárquicas - evoluem através de práticas culturais com base em relações humanas reais e restritas por arranjos materiais que restringem, mas não determinam. A solidariedade criativa preocupa-se com a multiplicidade de práticas culturais que podem evoluir nesses encontros, como forma de combater as versões de "cultura" e "identidade" que são impostas pelo projeto colonial da modernidade. O desafio para os trabalhadores culturais reside na reapropriação de conceitos como "cultura" e "identidade", "de modo que leve o olhar do leitor de volta às injustiças sociais e econômicas negligenciadas e desviadas" pelas condições presentes (WONG, 2011, p. 159). A solidariedade criativa trabalha para revelar novos horizontes, contra os quais podemos não apenas imaginar, mas também produzir novas formas de estar juntos. Obviamente, como Rita Wong nos lembra:

não há garantias de que a representação cultural não repita a violência que já ocorreu.
No entanto, nos casos em que o silêncio também parece ser uma cumplicidade
igualmente e talvez até mais insatisfatória com - e perpetuar - essa violência, táticas
de visibilidade problemática fornecem uma linha ética de compromisso que é
promissora. (2011, p. 159)

Essa é a promessa de solidariedade criativa; a possibilidade de que novas formas de fazer, de sentir, de criar, de amar: "enquanto sofremos os velhos anseios, lutem contra os velhos avisos e medos de ficar calados, impotentes e sozinhos, enquanto experimentamos novas possibilidades e forças" (LORDE, 1984, p. 39).

\section{DESCOLONIZAÇÃO E A PEDAGOGIA DA SOLIDARIEDADE}

Dinâmicas sociais, culturais, históricas, geográficas e políticas complexas, produziram um mundo de movimento intensificado no qual as linhas entre local e global são difundidas, onde indígenas/colonos, colonizadores/colonizados e opressores/oprimidos parecem apenas atenuar, quando na verdade tornam-se compulsórios e reinscritos. Essa aparição "serve para ocultar a realidade bruta de que a América do século XXI fomenta colônias internas" (GRANDE, 2004, p. 5); mascara apenas o fato de que alguns se beneficiam mais do que outros da situação atual (e também exonera de culpa quem se beneficia). Tais disseminações refletem as condições que produzem encontros coloniais e a própria "colonialidade" do ser (WYNTER, 2003). Isso requer que comecemos nossa análise das condições presentes, como observa Wynter:

com a situação empírica de hoje da subjugação, marginalização e deslocamento contínuos dos povos indígenas. Esse deslocamento é perpetuado não apenas pelos 
brancos da América do Norte e os mestizos ${ }^{20}$ da América Latina, mas também por novas ondas de imigrantes externos de todas as raças, culturas, religiões, de todas as partes do mundo - todos em busca de padrões de vida mais altos que devem ser observados em $80 \%$ do mundo que devem se contentar com $20 \%$ dos recursos do mundo, enquanto nossos $20 \%$ dispõem de $80 \%$ e são além disso responsáveis por $75 \%$ da poluição da Terra. (1995, p. 8)

Nesta era do capitalismo de desastre, em que as faltas de liberdades da democracia liberal estão indo além do subtexto, do currículo oculto e se tornando a lógica explícita e inquestionável de um neoliberalismo alimentada pelo choque, pelo medo de um desastre econômico e ecológico iminente e desenfreado (KLEIN, 2007), como podemos proceder? Que tipos de relações humanas seremos capazes de buscar, que possam constituir resistência e, talvez, curar-se da invasão e colonização contínuas?

A pedagogia da solidariedade tem como premissa uma fé profunda nas capacidades imaginativas dos seres humanos para transformar as condições - e, portanto, as definições - de sua existência. Sylvia Wynter ressalta essa capacidade quando observa que "nos inscrevemos e auto instituímos como pessoas humanas por meio de processos representativos simbólicos que, até agora, incluíram esses mecanismos de ocultação por meio dos quais fomos capazes de ofuscar para nós mesmos o fato do que fazemos"(2003, p. 328). Essa ocultação tem sido necessária para justificar o genocídio, a escravidão e a colonização, todos os processos que definem os vários gêneros de seres humanos atualmente disponíveis. É essa capacidade de repensar o humano que viabiliza o projeto de descolonização e, como argumenta Sharon Todd, repensar o humano e suas relações- sempre foi um problema educacional; "Se pensarmos que a humanidade realmente existe no ponto em que reconhecemos o risco de sua impossibilidade, então a educação pode ser repensada como um local de resposta à diferença humana" (2009, p. 20).

Tal resposta requer um profundo compromisso com o amor, entendido, nos termos de Sandoval, "como hermenêutica, como um conjunto de práticas e procedimentos ... em direção a um modo diferencial de consciência e suas tecnologias associadas de método e movimento social" (2000, p. 140) Essas práticas, como discutido anteriormente, devem tomar como ponto de partida o contexto particular e as experiências daqueles que sofreram as consequências mais danosas, resultantes das concepções atuais do que significa sermos pessoas humanas: as vítimas de genocídio, escravidão e guerras da conquista. ${ }^{21}$ São estes atos muito humanos que produziram as condições devastadoras do

\footnotetext{
${ }^{20}$ N. da RT: mantivemos a expressão na forma, em espanhol, que aparece originalmente no artigo em inglês.

${ }^{21}$ Obviamente, isso inclui sujeitos queer, bem como aqueles que são "deficientes" pelos arranjos sociais e concepções sociais atuais do ser humano, particularmente em categorias como "queer" e "deficientes" se cruzam com outros marcadores de diferença (EREVELLES , 2011; SMITH, 2010).
} 
deslocamento, bem como as ricas oportunidades para novos encontros entre aqueles entendidos como "Outros"; entre estes estranhos e aqueles estranhos, ambos sempre constituídos, mas nunca completamente determinados pelo olhar humano/homem, "dissecados sob olhos brancos, os únicos olhos reais" (FANON, 1967, p. 87).

Em certo sentido, o encontro entre comunidades indígenas e diaspóricas, no contexto do estado colonial e dos colonizadores, é um dos mais espinhosos e também um dos mais promissores quando se trata de pensar através da pedagogia da solidariedade. Nestes encontros que os projetos de solidariedade são frequentemente interrompidos, por diferentes experiências de opressão e diferentes ideias sobre como resistir à supremacia branca. Dentro da lógica da supremacia branca, o que surge como solução razoável para os problemas de alguns grupos marginalizados, se torna as condições opressivas para outros (SMITH, 2006).

Por exemplo, quando as comunidades diaspóricas na Ilha da Tartaruga (América do Norte) respondem às condições de deslocamento, gerando narrativas contraculturais de lugar e pertença, elas estão efetivamente participando da colonização em curso de terras indígenas (LAWRENCE, DUA, 2005). Por outro lado, uma concepção primordial ou autóctone de ser indígena ignora amplamente "as complexas redes de interdependência que ligam as pessoas umas às outras" (SHARMA, WRIGHT, 2008, p. 97). Ignora, por exemplo, a relação complexa e ambivalente que muitos negros e latinos têm com seus ancestrais indígenas, os quais, como Zainab Amadahy escreve, "nunca formaram o núcleo de suas identidades culturais, claramente um testemunho da eficácia do projeto genocida perpetrado nas Américas "(AMADAHY, LAWRENCE, 2009, p. 107; GAZTAMBIDEFERNÁNDEZ, GUERRERO, 2010).

No contexto de estados coloniais colonizadores, como os Estados Unidos e o Canadá, os indígenas e os negros são constituídos como "Outros" - como os estrangeiros internos -, mas não do mesmo tipo de estrangeiro. Enquanto o "Outro" indígena representa a estranheza do estado desaparecendo/desaparecido da natureza; o "Outro" diaspórico moreno/negro, representa a estranheza do perigo imanente e a perspectiva de terror. Ambos têm a subjetividade negada, mas nenhum deles pode reivindicar inocência. De fato, nenhum dos dois "pode insistir que a primazia de seu próprio sofrimento e impotência seja tão única e abrangente, que apague até a possibilidade de manterem relações de opressão em relação a outro grupo" (AMADAHY, LAWRENCE, 2009, p. 109). Como argumenta Sherene Razack, ninguém é isento e todos "estão

envolvidos na crise de nossos tempos" (2004, p. 14). Ou, como Eve Tuck e K. Wayne Yang (2012) colocam, a descolonização "implica e desestabiliza a todos" (p. 7). 
É com isso em mente que a pedagogia da solidariedade deve ser tomada, não como uma solução, mas como um modo através do qual se empenhar em práticas descolonizadoras. Isso requer a descolonização articulada, nos termos de Chandra Mohanty (2003), como um "interesse comum" que una os povos racializados e indígenas em suas diferenças na luta solidária. Enquanto Mohanty descreve o contexto da política de solidariedade entre as trabalhadoras, a distinção que ela faz entre interesses comuns, por um lado, e necessidades, desejos e escolhas, por outro, é útil aqui:22 “O teor das necessidades e desejos desde o ponto de vista do interesse, permanecem abertos à interpretação subjetiva "(p. 162). Isso, como aponta Mohanty, "às vezes milita contra a organização com base em [um] interesse comum" (p. 163). Isso significa que os três modos da pedagogia da solidariedade, devem começar com a premissa de que esse processo "é uma questão desconfortável, reservada e instável que não reconcilia as queixas presentes nem exclui conflitos futuros" (TUCK, YANG, 2012, p. 3); solidariedade, parafraseando Lorenzo Veracini (2011), não é descolonização.

Embora comprometida, em princípio, com o interesse comum da descolonização, a pedagogia da solidariedade não pode determinar a priori que tipos de alegações são relevantes para uma determinada instância, porque depende das particularidades e complexidades dos desejos e necessidades locais (TUCK, 2009). Em outras palavras, por ser relacional, a pedagogia da solidariedade exige que exploremos "as realidades fundamentadas que podem ajudar a esclarecer as relações" (AMADAHY, LAWRENCE, 2009, p. 106). Isso requer uma mudança para um conjunto diferente de termos para se envolver com diferenças que não carreguem a "linguagem conciliatória vaga do multiculturalismo e o desfile da diferença étnica” (SEHDEV, 2011, p. 273), nem o racionalismo individual eurocêntrico do cosmopolitismo (BHIMANI, GAZTAMBIDEFERNÁNDEZ, 2011). A linguagem das "relações de pacto e acordo", por exemplo, fornece "a base dos relacionamentos e para os pertencentes não aborígines a essa terra” (SEHDEV, 2011, p. 272). Como explica Robinder Kaur Sehdev:

A mudança para o tratado é importante também em termos de formação solidária entre os aborígines e os não aborígines não brancos, porque apresenta a possibilidade de desenvolver espaços discursivos, onde podemos começar a explorar nossa relação com um "outro"' dentro de um estado racista e colonizador. (2011, p. 272)

Naturalmente, a linguagem do acordo também é suscetível à colonização e, como apontam Amadahy e Lawrence (2009), tratados podem ser quebrados, podem trabalhar para estender a

\footnotetext{
${ }^{22}$ Mohanty credita à Anne Jónasdóttir (1988) essa distinção e oferece a seguinte citação de seu trabalho: "Entendidos historicamente e vistos como emergentes das experiências vividas das pessoas, os interesses sobre os processos básicos da vida social são divididos sistematicamente entre grupos de pessoas, na medida em que suas condições de vida são sistematicamente diferentes. Assim, definidos histórica e socialmente, os interesses podem ser caracterizados como “objetivos"”. (MOHANTY, 2003, p. 162).
} 
colonização e, às vezes, são baseados em termos que podem parecer insustentáveis sob condições de colonização em andamento (VERACINI, 2011). Ainda assim, como Sehdev sugere, podemos "focar a atenção no acordo de descolonização", passando de "uma compreensão do tratado como um artefato histórico, [para] um tratado como processo de criação e manutenção de boas relações". "Afinal", ela observa, o "tratado" é o espaço onde o poder é negociado" (2011, p. 273).

Uma solidariedade relacional exige que reconheçamos histórias pessoais complexas e, às vezes, contraditórias que nos unem em relações de acordo baseados no compromisso com a descolonização. Devemos fazê-lo, evitando as pretensões de inocência com base nessas histórias e reconhecendo as maneiras complicadas pelas quais tanto participamos, quanto resistimos aos processos de colonização. Isso requer o reconhecimento e a negociação do duplo vínculo, enquanto excessiva, pela subjetividade colonizada. De fato, é o excesso que abre, para usar as palavras de Fanon, "a porta de toda consciência" (1967, p. 181), oferecendo a oportunidade para uma reconstrução coletiva e criativa de nossa subjetividade compartilhada. "É através do esforço de recuperar o eu e de examiná-lo, é através da tensão duradoura de sua liberdade que os homens serão capazes de criar as condições ideais de existência para um mundo humano" (p.181). Isto também requer a prática da solidariedade transitiva, do comprometimento com ações que transformam ambos os lados da equação solidária, para a "dimensão pedagógica e transformadora" do comprometimento com os desejos e necessidades locais (MOHANTY, 2003, p. 162).

A pedagogia da solidariedade exige uma profunda fé nas possibilidades criativas que se tornam disponíveis quando nos reconhecemos em cada um (e cada "Outro") à medida que nos reunimos com base em um compromisso de descolonização que, "deve enfatizar a franqueza. A reconciliação deve ser uma prática e não um processo" (2011, p. 9). Como Sylvia Wynter, citando Fanon, nos lembra no final de seu importante ensaio: "Desestabilizando a Colonialidade do Ser/Poder/Verdade/Liberdade":

"O verdadeiro salto", escreveu Fanon no final de seu livro "Peles Negras, Máscaras Brancas", "consiste em introduzir a invenção na existência". O colonialismo para $\operatorname{conosco}^{23}(2003$, p. 331)

\footnotetext{
${ }^{23}$ Nota da RT: The buck stops with us é uma expressão usada para enfatizar que a responsabilidade final de tomar uma decisão ou tomar uma ação cabe à pessoa que usa a frase, e, o idioma. Buck, então, pode significar dinheiro, dólar, macho, pulo, pênis, etc.
} 


\section{REFERÊNCIAS}

AHMED, S.. Strange encounters: Embodied others in post-coloniality. New York:

Routledge, 2000.

ALCOFF, L.. Who's afraid of identity politics? In MOYA, P. ; GARCIA, M.. H. (Eds.). Reclaiming identity: Realist theory and the predicament of postmodernism. Berkeley, CA: University of California Press, p. 312-337, 2000.

AMADAHY, Z.; LAWRENCE, B.. Indigenous peoples and Black people in Canada: Settlers of allies? In KEMPF, A. (Ed.). Breaching the colonial contract: Anti-colonialism in the U.S. and Canada. New York: Springer. p. 105-136, 2009. Disponível em: http://www.yorku.ca/laps/des/conference/documents/Indigenous\%20Peoples\%20and\%20 Black\%20People\%20in\%20Canada.pdf. Acesso em: 10.dez.2019.

BANKS, J. A.. Multicultural education: Characteristics and goals. In BANKS, J. A.; MCGEE, C. A. (Eds.), Multicultural education: Issues and perspectives. Boston, MA: Wiley \& Sons, 9ª ed., p. 3-32, 2009.

BANNERJI, H.. The dark side of the nation: Essays on multiculturalism, nationalism and gender. Toronto: Canadian Scholars' Press, 2000.

BAUMAN, Z.. Happiness in a society of individuals. Soundings, (38), p.19-28, 2008

BAYERTZ, K.. Four uses of “solidarity”. In BAYERTZ, K. (Ed.). Solidarity. Dordrecht: Kluwer Academic Publishers, p. 3-28, 1999.

BECK, U. (Ed.). The reinvention of politics: Rethinking modernity in the global social order. Cambridge, Eng.: Polity Press, 1997.

BHIMANI, S.; GAZTAMBIDE-FERNÁNDEZ, R.. Specters of Kant: Can there be a post-colonial cosmopolitanism? Paper presented at the Annual Curriculum and Pedagogy Conference, Akron, OH, 2011.

BUTLER, J.. Excitable speech: A politics of the performative. New York: Routledge, 1997.

CALHOUN, C.. Constitutional patriotism and the public sphere: Interests, identity, and solidarity in the integration of Europe. International Journal of Politics, Culture, and Society, 18(3-4), 257-280, 2006.

CHOULIARAKI, L.. 'Improper distance': Towards a critical account of solidarity as irony. International Journal of Cultural Studies, 14(4), 363-381, 2011.

CROW, G.. Social solidarities: Theories, identities, and social change. Philadelphia, PA: Open University, 2002.

DAY, R.. Multiculturalism and the history of Canadian diversity. Toronto: University of Toronto Press, 2000.

DEAN, J.. Solidarity of strangers: Feminism after identity politics. Berkeley: University of California Press, 1996.

DUBOIS, W. E. B.. The souls of Black folk: Essays and sketches. New York: Fawcett Publications, 1961.

EREVELLES, N.. Disability and difference in global contexts: Enabling a transformative body politic. New York: Palgrave Macmillan, 2011.

FANON, F.. Pele negra, mascaras brancas [Black skin, white masks] (C. L. Markman Trans.). New York: Grove Press, 1967.

FREIRE, P.. Pedagogia do Oprimido [Pedagogy of the oppressed]. New York: Continuum, 1970/2005.

GAZTAMBIDE-FERNÁNDEZ, R.. Singing the abject and listening obliquely. In DUVALL, L. (Ed.), Where were the mothers? Exhibition catalogue. Mississauga, ON: Art Gallery of Mississauga, p. 37-41, 2009.

GAZTAMBIDE-FERNÁNDEZ, R.; GUERRERO, C.. ¿Cómo migra la teoría? Applications, implications, and limitations for understanding US-based theorizing on Latin@ immigration in Canada. Paper presented at the Canadian Association for Latin American and Caribbean Studies, Bi-Annual Meeting, Montreal, QC, 2010.

GOLDBERG, D. T. (Ed.). Multiculturalism: A critical reader. Oxford: Blackwell, 1994.

GOONEWARDENA, K.; KIPFER, S.. Spaces of difference: Reflections from Toronto on multiculturalism, bourgeois urbanism and the possibility of radical urban politics. International Journal of Urban and Regional Research, 29(3), p. 670-678, 2005.

GRANDE, S.. Red pedagogy: Native American social and political thought. Lanham, MD: Rowman \& Littlefield, 2004.

HALL, S.. Notes on deconstructing 'the popular'. In SAMUEL, R. (Ed.). People's history and socialist theory. London: Routledge, p. 227-240, 1981. 
HALL, S.. The problem of ideology-Marxism without guarantees. Journal of Communication Inquiry, 10(2), p. 28-44, 1986.

HALL, S.. The west and the rest: Discourse and power. In HALL, S.; GIEBEN, B. (Eds.). Formations of modernity . Cambridge: Polity, p. 184-227, 1992.

HANSEN, D. T.. Curriculum and the idea of a cosmopolitan inheritance. Journal of Curriculum Studies, 40(3), p. 289312, 2008.

HANSEN, D. T.. Cosmopolitanism and education: A view from the ground. Teachers College Record, 112(1), p. 1-30, 2010.

HARVEY, D.. Cosmopolitanism and the geographies of freedom. New York: Columbia University Press, 2009.

HOELZL, M.. Recognizing the sacrificial victim: The problem of solidarity for critical social theory. Journal for Cultural and Religious Theory, 6(1), p. 45-64, 2005.

JAMESON, F.. Postmodernism, or, the cultural logic of late capitalism. New Left Review, 146, p. 59-92, 1984.

JÓNASDÓTTIR, A.. On the concept of interests, women's interests, and the limitations of interest. In JONES, K.; JÓNASDÓTTIR, A. (Eds.). The political interests of gender: Developing theory and research with a feminist face . London: Sage, p. 33-65, 1988.

KANPOL, B.. Multiculturalism and empathy: A border pedagogy of solidarity. In KANPOL, B.; MCLAREN, P.(Eds.). Critical multiculturalism: Uncommon voices in a common struggle. Westport, CT: Bergin \& Garvey, p. 177-198, 1995.

KANPOL1, B.; MCLAREN, P. (Eds.). Critical multiculturalism: Uncommon voices in a common struggle. Westport, CT: Bergin \& Garvey, 1995.

KANT, I.. A paz perpétua: um projeto filosófico [Perpetual peace: A philosophical essay](M. Campbell Smith Trans.). London: George Allen \& Unwin LTD, 1795/1917.

KHALDUN, I.. The muqaddimah: An introduction to history [Kitāb al-'ibar.] (F. Rosenthal Trans.). Princeton, NJ: Princeton University Press, 2005

KLEIN, N.. The shock doctrine: The rise of disaster capitalism. Toronto: A.A. Knopf Canada, 2007.

LADSON-BILlingS,G. ; BROWN, K.. Curriculum and cultural diversity. In CONNELly, F. M., HE, M. F.; PHILLION, J. (Eds.). The handbook of curriculum and instruction. Thousand Oaks, CA: Sage. p. 153-175, 2008.

LAWRENCE, B.; DUA, E.. Decolonizing antiracism. Social Justice, 32(4), p. 120-143, 2005.

Disponível em: http://racismandnationalconsciousnessresources.files.wordpress.com/2008/11/bonita-lawrencedecolonizing-anti-racism.pdf. Acesso em: 10.dez.2019.

LORDE, A.. Sister outsider: Essays and speeches. Trumansburg, NY: The Crossing Press, 1984.

MACEDO, D.. Introduction. In FREIRE, P.. Pedagogy of the oppressed. New York: Continuum, p. 11-28, 2005.

MARX, K.; ENGELS, F. A ideologia alemã [The German ideology] (R. Pascal Trans.). New York: International Publishers, 1967.

MCCARTHY, C.; REZAI-RASHTI, G.; TEASLEY, C.. Race, diversity, and curriculum in the era of globalization. Curriculum Inquiry, 39(1), p. 75-96, 2009.

MIGNOLO, W.. The many faces of cosmo-polis: Border thinking and critical cosmopolitanism. Public Culture, 12(3), p. 721-748, 2000.

MOHANTY, C. T.. Feminism without borders: Decolonizing theory, practicing solidarity. Durham, NC: Duke University Press, 2003.

NANCY, J.. Being singular plural. Stanford, CA.: Stanford University Press, 2000.

NANCY, J.. The inoperative community. Minneapolis, MN: University of Minnesota Press, 1991.

NIETO, S. et al. Identity, community, and diversity: Retheorizing multicultural curriculum for the postmodern era. In CONNELY, F. M.; HE, M. F; PHILLION, J.(Eds.). The handbook of curriculum and instruction. Thousand Oaks, CA: Sage, p. 176-197, 2008.

NIETO, S.; BODE, P.. Affirming diversity: The sociopolitical context of multicultural education. Boston: Pearson, $6^{\mathrm{a}}$ ed, 2012.

OTTMAN, J.. The concept of solidarity in national and European law: The welfare state and 
the European social model. ICL: Vienna Journal on International Constitutional Law, 2(1), p. 36-48, 2008. Disponível em:

http://www.internationalconstitutionallaw.net/download/23854f4d5cd21d72d92eb3af39f3bb34/Ottmann.pdf. Acesso em: 10.dez.2019.

PHILLIPS, A.. Multiculturalism without culture. Princeton, N.J.: Princeton University Press, 2007.

PINAR,, W.. The worldliness of a cosmopolitan education: Passionate lives in public service. New York: Routledge, 2009.

POPKEWITZ, T. S.. The double gestures of cosmopolitanism and comparative studies of education. In COWEN, R.; KAZAMIA, A. (Eds.). International handbook of comparative education. New York: Springer, p. 385-4-1, 2009.

POPKEWITZ, T. S.. Cosmopolitanism and the age of school reform: Science, education, and making society by making the child. New York: Routledge, 2007.

RAZACK, S.. Dark threats and white knights: The Somalia affair, peacekeeping, and the new imperialism. Toronto: University of Toronto Press, 2004.

RAZACK, S.. Looking white people in the eye: Gender, race, and culture in courtrooms and classrooms. Toronto: University of Toronto Press, 1998.

RICHARDSON, T.. Navigating the problem of inclusion as enclosure in native culture-based education: Theorizing shadow curriculum. Curriculum Inquiry, 41(3), p. 332-349, 2011.

RORTY, R.. Contingency, irony, and solidarity. Cambridge, Eng.: Cambridge University Press, 1989.

SANDOVAL, C.. Methodology of the oppressed. Minneapolis, MN: University of Minnesota Press, 2000.

SAWYER, K.. Extending sociocultural theory to group creativity. Vocations and Learning, 5(1), p. 59-75, 2012.

SAWYER, K.; DEZUTTER, S.. Distributed creativity: How collective creations emerge from collaboration. Psychology of Aesthetics, Creativity, and the Arts, 3(2), p. 81-92, 2009.

SCHOLZ, S. J.. Political solidarity. University Park, PA.: Pennsylvania State University Press, 2008.

SEHDEV, R.. People of colour in treaty. In MATHUR, A.; DEWAR, J.; DEGAGNÉ, M. (Eds.), Cultivating Canada: Reconciliation through the lens of cultural diversity. Ottawa, ON.: Aboriginal Healing Foundation, p. 263-274, 2011.

SENNETT, R.. A corrosão do caráter: consequências pessoais do trabalho no novo capitalismo [The corrosion of character: The personal consequences of work in the new capitalism]. New York: Norton, 1998.

SHAMA, N.; WRIGHT, C.. Decolonizing resistance, challenging colonial states. Social Justice, 35(3), p. 120-138, 2008.

SMITH, A.. Queer theory and native studies: The heteronormativity of settler colonialism. GLQ: A Journal of Lesbian and Gay Studies. 16(1-2), p. 42-68, 2010.

SMITH, A.. Heteropatriarchy and the three pillars of white supremacy: Rethinking women of color organizing. In INCITE! Women of Color Against Violence (Eds.), Color of violence: The INCITE! Anthology. Cambridge, MA: South End Press, P. 66-73, 2006.

SPIVAK, G. C.. A critique of postcolonial reason: Toward a history of the vanishing present. Cambridge, MA: Harvard University Press, 1999.

STJERNO, S.. Solidarity in Europe: The history of an idea. Cambridge, Eng.: Cambridge University Press, 2005.

TARC, A. M.. Curriculum as difficult inheritance. Journal of Curriculum \& Pedagogy, 8(1), p. 17-19, 2011.

TAYLOR, A.. Examined life. [Video/DVD] Toronto: Zeitgeist Film, 2008.

TODD, S.. Toward an imperfect education: Facing humanity, rethinking cosmopolitanism. Boulder, CO: Paradigm Publishers, 2009.

TODD, S.. Bringing more than I contain: Ethics, curriculum and the pedagogical demand for altered egos. Journal of Curriculum Studies, 33(4), p. 431-450, 2001.

TUCK, E.. Suspending damage: A letter to communities. Harvard Educational Review, 79(3), p. 409-428, 2009. Disponível em: http://dss.ucsd.edu/ rfrank/class_web/ES-114A/Week\%204/TuckHEdR79-3.pdf. Acesso em: 10.dez.2019.

TUCK, E.; GAZTAMBIDE-FERNAÁNDEZ, R. (no prelo). Curriculum, replacement, and settler futurity. 
TUCK, E.; YANG, K. W.. Decolonization is not a metaphor. Decolonization: Indigeneity, Education, \& Society, 1(1), p. 1-40, 2012.

VERACINI, L.. Introducing settler colonial studies. Settler Colonial Studies, 1(1), p. 1-12, 2011. Disponível em:

http://ojs.lib.swin.edu.au/index.php/settlercolonialstudies/article/view/239/223. Acesso em: 10.dez.2019.

WALCOTT, R.. Black like who?. Toronto: Insomniac Press, 2a ed., 2003.

WEBER, M.. Class, status, party. In GERTH, H. H.; MILLS, C. W. (Eds.). From Max Weber: Essays in sociology . New York: Oxford University Press, p. 180-195, 1946

WILLIAMS, R.. Marxism and literature. Oxford: Oxford University Press, 1977.

WILLIS, P.. Notes on common culture: Towards a grounded aesthetic. European Journal of Cultural Studies, 1(2), p. 163-176, 1998.

WILLIS, P.. Common culture: Symbolic work at play in the everyday cultures of the young. San Francisco: Westview Press, 1990.

WONG, R.. Decolonizasian: Reading Asian and first nations relations in literature.

Canadian Literature, 199, p. 158-180, 2008.

WYNTER, S.. Unsettling the coloniality of being/power/truth/freedom: Towards the human, after man, its overrepresentation--An argument. CR: The New Centennial Review, 3(3), p. 257-337, 2003.

WYNTER, S.. 1492: A new world view. In HYATT, V. L.;NETTLEFORD, R. (Eds.).

Race, discourse, and the origin of the Americas: A new world view. Washington: Smithsonian Institute, P. 5-57, 1995.

YOUNG, I. M.. Inclusion and democracy. Oxford: Oxford University Press, 2002.

Resumo

O conceito de solidariedade é frequentemente evocado nos projetos de descolonização. Mais recentemente, no entanto, o fracasso em construir relacionamentos solidários que envolvam seriamente as demandas colocadas pela descolonização, provocou ceticismo e suspeita quanto à viabilidade da solidariedade. Uma consideração da genealogia, bem como dos múltiplos usos do conceito de solidariedade, revela algumas das maneiras pelas quais o conceito reinscreve a lógica colonial e opera para obscurecer a cumplicidade e a continuação da colonização. Ao mesmo tempo, é possível articular um conjunto de parâmetros para relações solidárias, através dos quais se constrói imaginativamente novas maneiras de entrar em relações com os outros. De fato, quando informada pelas falhas de respostas, como foram o multiculturalismo e o cosmopolitismo ao problema da diferença humana, a solidariedade continua sendo uma possibilidade importante. Este artigo propõe três meios para uma pedagogia da solidariedade comprometida com a descolonização. Defende as possibilidades de solidariedade relacional, transitiva e criativa como estratégia para reformular não apenas as relações humanas, mas também a própria noção do que significa ser humano, o que é crucial para a descolonização.

Palavras-chave: solidariedade, pedagogia, decolonização, analise cultural

\section{Abstract}

The concept of solidarity is often evoked within projects of decolonization. More recently, however, the failure to construct solidary relationships that seriously engage the demands posed by decolonization has provoked skepticism as well as suspicion regarding the viability of solidarity. A consideration of the genealogy as well as the multifarious uses of the concept of solidarity reveals some of the ways in which the concept reinscribes colonial logics and operates to obscure complicity and continued colonization. At the same time, it is possible to articulate a set of parameters for solidary relations through which to imaginatively construct new ways of entering into relations with others. In fact, when informed by the failures of responses such as multiculturalism and cosmopolitanism to the problem of human difference, solidarity remains an important possibility. This article proposes three modes for a pedagogy of solidarity that is committed to decolonization. It argues for the possibilities of relational, transitive, and creative solidarity as a strategy for recasting not only human relations but also the very notion of what it means to be human, as crucial for decolonization. 
Keywords: solidarity, pedagogy, decolonization, cultural analysis

\section{Resumen}

El concepto de solidaridad a menudo se evoca dentro de los proyectos de descolonización. Más recientemente, sin embargo, el fracaso en la construcción de relaciones solidarias que comprometan seriamente las demandas planteadas por la descolonización ha provocado escepticismo y sospecha sobre la viabilidad de la solidaridad. Una consideración de la genealogía, así como los múltiples usos del concepto de solidaridad revela algunas de las formas en que el concepto reinscribe las lógicas coloniales y opera para ocultar la complicidad y la colonización continua. Al mismo tiempo, es posible articular un conjunto de parámetros para las relaciones solidarias a través de las cuales construir imaginativamente nuevas formas de entablar relaciones con los demás. De hecho, cuando se informa por las fallas de respuestas como el multiculturalismo y el cosmopolitismo al problema de la diferencia humana, la solidaridad sigue siendo una posibilidad importante. Este artículo propone tres modos para una pedagogía solidaria comprometida con la descolonización. Defiende las posibilidades de solidaridad relacional, transitiva y creativa como estrategia para reformular no solo las relaciones humanas sino también la noción misma de lo que significa ser humano, como crucial para la descolonización.

Palabras clave: solidaridad, pedagogía, descolonización, análisis cultural.

Submetido em Agosto de 2019

Aprovado em Dezembro de 2019 